\section{Terminal valve of sapheno-femoral junction: a comparative assessment between pre-operative color-duplex ultrasound and intra-operative evaluation}

Attilio Cavezzi, ${ }^{1,2,3}$ Valerio Carigi, ${ }^{2}$ Fausto Campana, ${ }^{4}$ Gianni Sigismondi, ${ }^{2}$ Concettina Elio, ${ }^{2}$ Sonia Di Paolo, ${ }^{1}$ Simone Ugo Urso, 1,3

'Vascular Unit, Clinic "Stella Maris" San Benedetto del Tronto (AP); ${ }^{2}$ Montefeltro Salute Hospital, Sassocorvaro (PU); ${ }^{3}$ Vascular Unit, Poliambulatorio Hippocrates, San Benedetto del Tronto (AP); ${ }^{4}$ Vascular Medicine Unit, Bufalini Hospital, Cesena, Italy

\section{Abstract}

According to literature data, up to $59 \%$ of incompetent great saphenous veins (GSV) have no reflux at the terminal valve (TV) of the saphenofemoral junction (SFJ). The aim was to compare color duplex ultrasound (CDU) investigation and direct intra-operative assessment of competence of the TV at SFJ.

A prospective comparative study was performed on 28 patients, who consecutively presented for surgical intervention for their primary varicose veins of the lower limbs with GSV incompetence. CDU assessment was performed pre-operatively to define GSV and SFJ terminal valve morphology and hemodynamics. Under local anesthesia these patients underwent SFJ disconnection (crossectomy) and segmental inverted saphenous stripping of the incompetent GSV tract + phlebectomy of the varicose tributaries. SFJ disconnection was performed in four stages in an ascending fashion: I) division of GSV below the lower SFJ tributaries, II) disconnection of lower SFJ tributaries, III) disconnection of upper tributaries, IV) flush to CFV ligature of GSV stump. After the completion of stage I, the SFJ stump was opened and kept open when needed throughout the subsequent stages, in order to highlight any possible blood leak through the SFJ stump. To highlight intraoperative blood leak from SFJ stump visual observation was carried out both during respiration and when performing Valsalva maneuver and manual compression of homolateral iliac fossa.

As to pre-operative CDU all limbs showed GSV reflux and they were divided in two groups according to TV competence (group A) or incompetence (group B). Group A comprised 18 patients (6 $\mathrm{M}$ and $12 \mathrm{~F}$ ), mean age 50.6 years.
Group B included 10 patients (4 M and $6 \mathrm{~F}$ ), mean age 54.8 years. Mean calibre of GSV at proximal/mid thigh was $6.4 \mathrm{~mm}$ in group $A$ and 7.8 in group $B$. Concerning the intra-operative findings: in the group A, 5 patients had blood leak in the SFJ stump after stage I, 4 patients showed blood leak after stage II. After completion of stage III, only one severely obese patient had persistent reflux, whereas 17 patients had no reflux. Conversely the 10 patients from group B had reflux within GSV stump throughout the 3 stages.

CDU pre-operative assessment matches intra-operative findings with regards to GSV TV competence/incompetence, with a good overall accuracy (27/28-94\%). Different SFJ retrograde flow patterns should be elicited through CDU investigation. Obese patients need a more thorough CDU examination to avoid false negatives.

\section{Introduction}

Varicose vein disease may be related to great saphenous vein (GSV) incompetence in many cases. In the past years sapheno-femoral junction (SFJ) was considered the key-point of the disease in the vast majority of the cases. In fact color-duplex ultrasound (CDU)-based literature repeatedly showed that several hemodynamic patterns can be highlighted in presence of GSV retrograde flow. There is growing evidence in literature data about the extremely frequent combination of GSV incompetence without any reflux through its terminal valve (TV) of SFJ. ${ }^{1-5}$

CDU investigation permits to map accurately all the incompetent segments of the GSV stem, also elucidating the morphologic and hemodynamic condition of SFJ. ${ }^{4,5}$ SFJ is a complex of a few veins, mostly five in number (including GSV, superficial epigastric vein, superficial circumflex iliac vein, pudendal vein/s, anterior accessory saphenous vein. Two valves are usually present in the uppermost part of GSV stem: the TV at the confluence between GSV and common femoral vein (CFV) and the pre-terminal valve (PTV), which is usually located below all the SFJ tributaries, above Giacomini vein entrance, just at the point where GSV crosses superficial fascia (Figure 1). PTV may be absent in up to $30 \%$ of the subjects, whereas TV is much more constant. ${ }^{6,7}$

The complexity of the possible morphologic and hemodynamic patterns at SFJ has been elucidated through CDU investigation and TV competence/incompetence represents a finding of paramount importance when treating varices related to GSV disease. ${ }^{8}$

The purpose of this observational comparative clinical and instrumental study has been to assess reliability of CDU investigation of TV of SFJ, in presence of GSV incompetence,
Correspondence: Attilio Cavezzi, Vascular Unit, Poliambulatorio Hippocrates, Via Miramare 7, 63074, San Benedetto del Tronto (AP), Italy. E-mail: info@cavezzi.it

Key words: terminal valve, duplex ultrasound, intra-operative assessment, great saphenous vein.

Acknowledgments: we sincerely thank Massimo Cappelli, Claude Franceschi, Sandro Pieri and Paolo Zamboni who significantly contributed to improve our knowledge on vein hemodynamics and indirectly stimulated our research.

Conflict of interests: the authors declare no potential conflict of interests.

Received for publication: 17 September 2012.

Revision received: 19 December 2012.

Accepted for publication: 7 January 2013.

This work is licensed under a Creative Commons Attribution 3.0 License (by-nc 3.0).

(C) Copyright A. Cavezzi et al., 2012

Licensee PAGEPress, Italy

Veins and Lymphatics 2012; 1:e9

doi:10.4081/vl.2012.e9

through the comparison between CDU findings and the intraoperative findings of the same patients during SFJ surgical disconnection (crossectomy).

\section{Materials and Methods}

A prospective comparative study was conducted in two Clinics, where varicose vein patients were referred for surgical treatment. A cohort of 28 previously investigated (history taking, clinical assessment and CDU evaluation) patients consecutively presented with primary varicose veins of the lower limbs and GSV incompetence, to be treated by means of stripping and phlebectomy. On the day of the surgical intervention the patients underwent CDU mapping, in order to define pre-operatively the morphological and hemodynamic condition of the varicose lower limb. Mean calibre of GSV trunk was measured through transverse scan at proximal and mid thigh, avoiding measurements where saccular dilations existed.

Through a standardised procedure,${ }^{5}$ patients were investigated in standing position, by means of compression/release and Valsalva maneuvers and testing each vein segment both with pulsed wave Doppler and with colorflow imaging, with transverse and longitudinal scanning. To elicit competence/incompetence of the GSV segments and of TV and PTV, the one-second cut-off was used to detect patho- 
logical reflux in the investigated venous tracts. Using a $10 \mathrm{MHz}$ linear probe, a color/Doppler flow setting of $8 \mathrm{~cm} / \mathrm{s}$. minimum speed was pre-fixed, in order to detect adequately also slow antegrade/retrograde flows. ${ }^{5}$

TV incompetence was diagnosed when reflux was highlighted within the $\mathrm{CFV}$, through the TV and within the uppermost segment of GSV immediately below TV (Figure 2). GSV incompetence combined with TV competence was characterized by the absence of any reflux in the CFV and the presence of retrograde flow within the GSV segment immediately below the TV (Figures 3-5). PTV incompetence was characterized by retrograde flow in the GSV trunk above and below this valve.

Through the CDU investigation as to above, the 28 patients were pre-operatively divided in two groups: i) group $\mathrm{A}$ which comprised patients with an incompetent GSV and a competent TV; ii) group B which included patients with an incompetent GSV and an incompetent TV.

All patients were operated in local anesthesia (buffered mepivacaine $0.25 \%$ and tumescence infiltration), according to our previously described procedure $^{9} \quad$ Sapheno-femoral crossectomy (flush ligation of GSV trunk at CFV level and disconnection of all SFJ tributaries) was combined with segmental inverted stripping of the refluxing tract of GSV. Varicose tributaries were avulsed by means of hook phlebectomy and mini-incisions.

In order to assess intra-operatively SFJ hemodynamics, and more specifically TV competence/incompetence, crossectomy was performed in four sequential stages in an ascending fashion. The first stage comprised the division of GSV trunk $3-4 \mathrm{~cm}$ below SFJ, with clamping of the distal GSV tract; the second stage included the disconnection of the lower SFJ tributaries (e.g. anterior accessory saphenous vein), and at the third stage the disconnection of upper tributaries (e.g. epigastric vein) of SFJ was performed. Once all tributaries were ligated and disconnected, the fourth stage included the final flush ligation of GSV at its confluence with CFV.

During the whole procedure, after stage I completion, the proximal GSV stump was opened and kept open (by means of a traumatic clamps and trying to avoid any stretching or compression on the GSV stump) when needed for TV testing. Throughout all stages, firstly a visual observation of any possible blood leak during normal respiration was performed, whereas subsequently Valsalva maneuver was performed by the patient (who was in semirecumbent position), in order to elicit blood reflux in the SFJ stump. An external physician repeatedly performed the compression of the homolateral iliac fossa during each of the first three stages, in order to check for blood reflux from CFV towards the SFJ open stump as well.

Once completed crossectomy, inversion stripping of the refluxing GSV tract + hook phlebectomy was performed, as to above.

\section{Results}

CDU investigation screened the 28 patients in the two groups according to GSV TV hemodynamics. More in detail group A (TV competence) comprised 18 patients ( 6 males and 12 females), mean age 50.6 years, and the $C$ variable repartition within CEAP classification was the following: 11 limbs C2, 4 limbs C3, 2 limbs C4, and one limb C5. Group B (TV incompetence) included 10 patients ( 4 males 6 females), mean age 54.8 years; CEAP subdivision of the varicose limbs as to $\mathrm{C}$ variable was as follows: 5 in $\mathrm{C} 2,2$ in $\mathrm{C} 3,2$ in

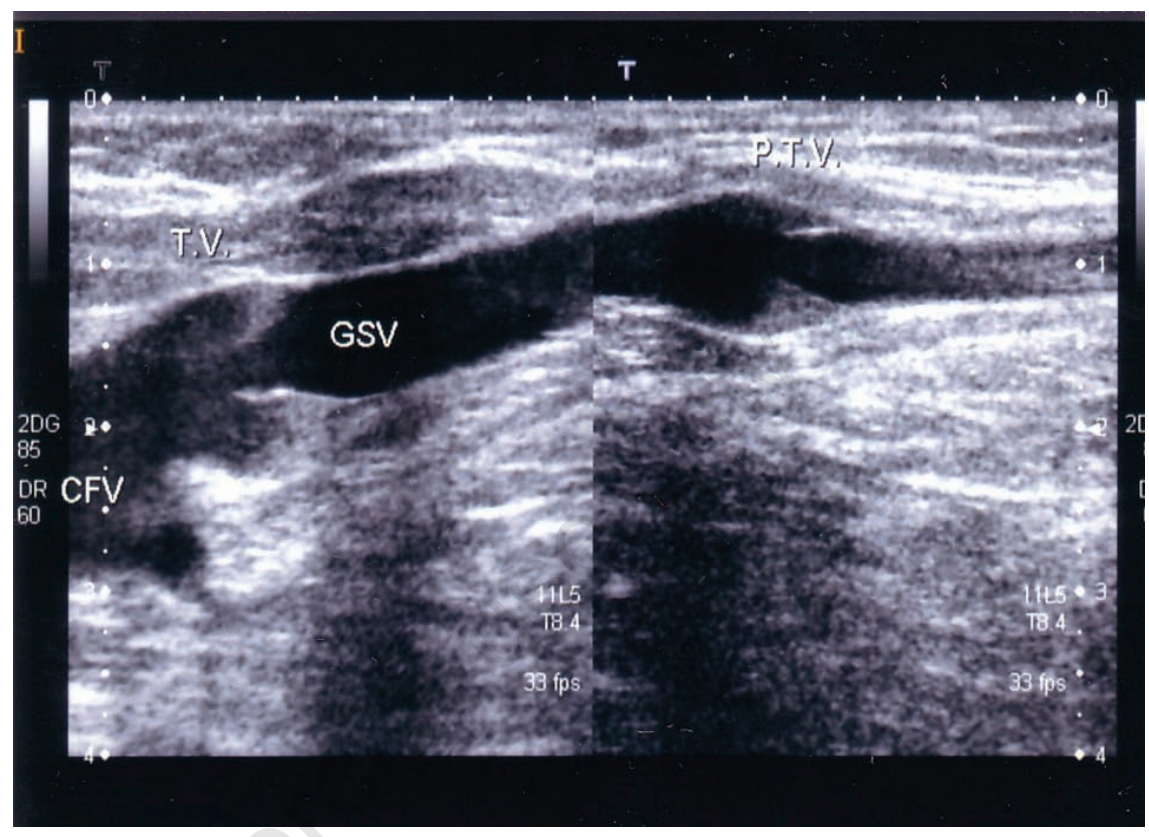

Figure 1. Ultrasound visualization of terminal valve and pre-terminal valve of great saphenous vein.

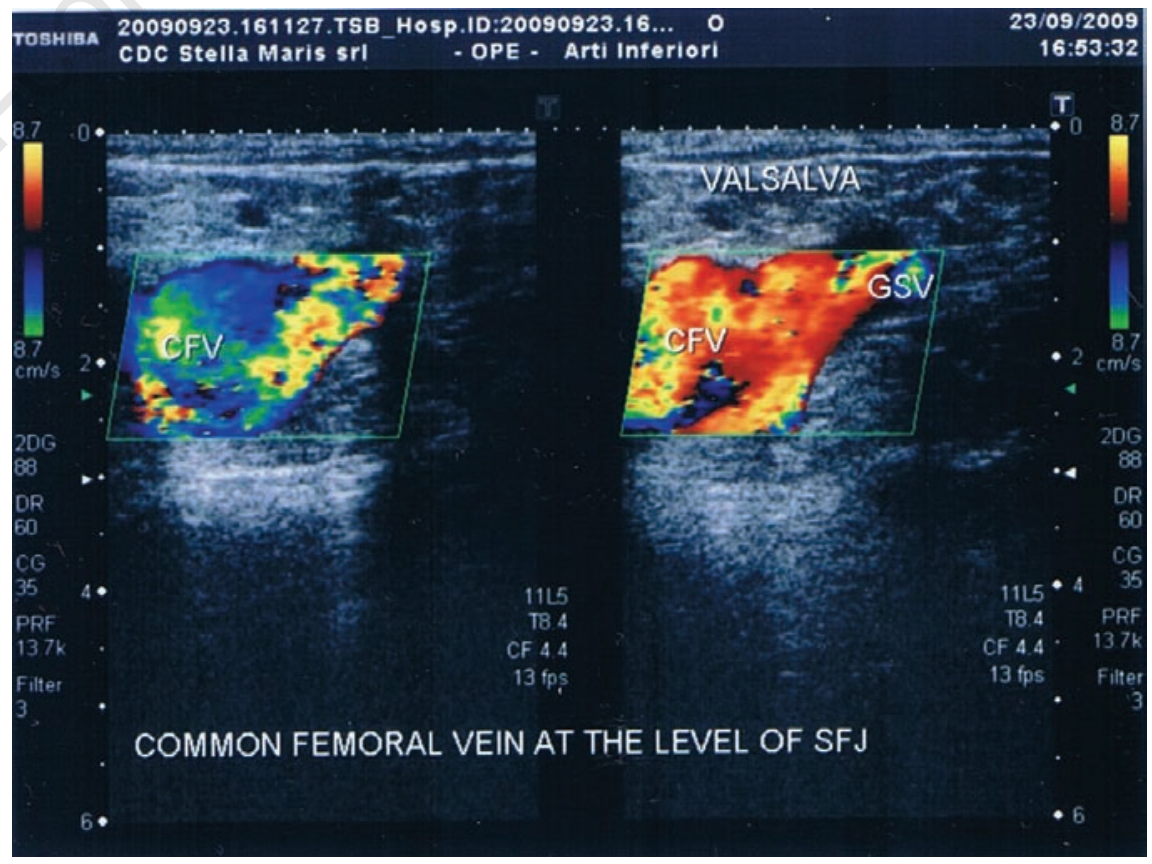

Figure 2. Color-duplex ultrasound of terminal valve incompetence at sapheno-femoral junction. 
C4 and one in C5.

Overall mean calibre of GSV trunk at proximal and mid thigh level was $6.4 \mathrm{~mm}$ (S.D. +/1.2) in limbs of group A and $7.8 \mathrm{~mm}$ (S.D. +/1.6) in limbs of group B.

The intra-operative assessment of SFJ stump during the four stages was performed and all findings were recorded subsequently. The findings differed significantly between the two groups and a summary of the main results of intraoperative assessment of SFJ stump is reported in Table 1.

Basically in group A (competence of TV at CDU pre-operative investigation), 13 patients showed no reflux in SFJ stump throughout the first three stages, while a spontaneous blood leak from SFJ stump was seen in five patients after the first stage, hence it disappeared in one of them after stage II completion. Finally after performing stage III, 17/18 patients in total showed no reflux from the open SFJ. One severely obese patient showed persistent reflux after completion of stage III. Once completed crossectomy (stage IV), no blood leak was visible in any patient.

The 10 patients in group B (TV incompetence), conversely, had blood leak/reflux within the open SFJ stump throughout the first 3 stages, both during respiration and performing Valsalva manoeuvre or iliac fossa compression. After completion of crossectomy (stage IV) no blood reflux was visualized in any case.

\section{Discussion}

SFJ represents a complex site both from the anatomy and from the hemodynamics point of view. TV is a fundamental part of SFJ and it is designed to prevent reflux from CFV into the superficial venous system. PTV is located just below the entrance of the 4-5 main SFJ tributaries, which contribute to constitute the ending part of GSV, also called saphenous cross or saphenous arch.

CDU study of this area may require different scanning approaches and maneuvers in order to understand its anatomy and hemodynamics properly. Due to the great importance of TV assessment before indicating a proper GSV treatment, ${ }^{8,10}$ an adequate diagnostic approach is needed to screen TV competence/incompetence. A proper setting of color-flow and Doppler module is helpful to pick up slow flows, as well as adequate and reproducible manoeuvres are to be used. ${ }^{5}$ Placing the Doppler and Color flow sample within CFV and through the TV, allows to reduce false positive diagnoses of valve incompetence, which are possible if sampling only GSV trunk just below TV.

On one side CDU literature data show 28$59 \%$ incidence of TV competence in limbs with primary varicose veins and GSV incompe- tence, ${ }^{1-5,8}$ on the other side TV seems to be affected by reflux at a later stage of the evolution of the varicose disease. ${ }^{11}$ Hence patients with GSV reflux and TV incompetence should be usually older than patients with TV competence. More importantly, limbs with GSV reflux have a smaller saphenous diameter (usually equal or below $5 \mathrm{~mm}$ at mid thigh) when TV is competent, whereas GSV diameter is larger (above $6 \mathrm{~mm}$ in more than $70 \%$ of the cases) when TV is incompetent. ${ }^{10}$ In our series GSV calibres were slightly higher, probably due to the fact that we calculated the mean value between proximal thigh and mid thigh GSV size. Interestingly the $60 \%$ (17/28) incidence of TV competence, in our 28 unselected consecutive patients, is slightly higher than the incidence reported in literature, ${ }^{1-5,8}$ which may depend upon the age of the investigated patients.

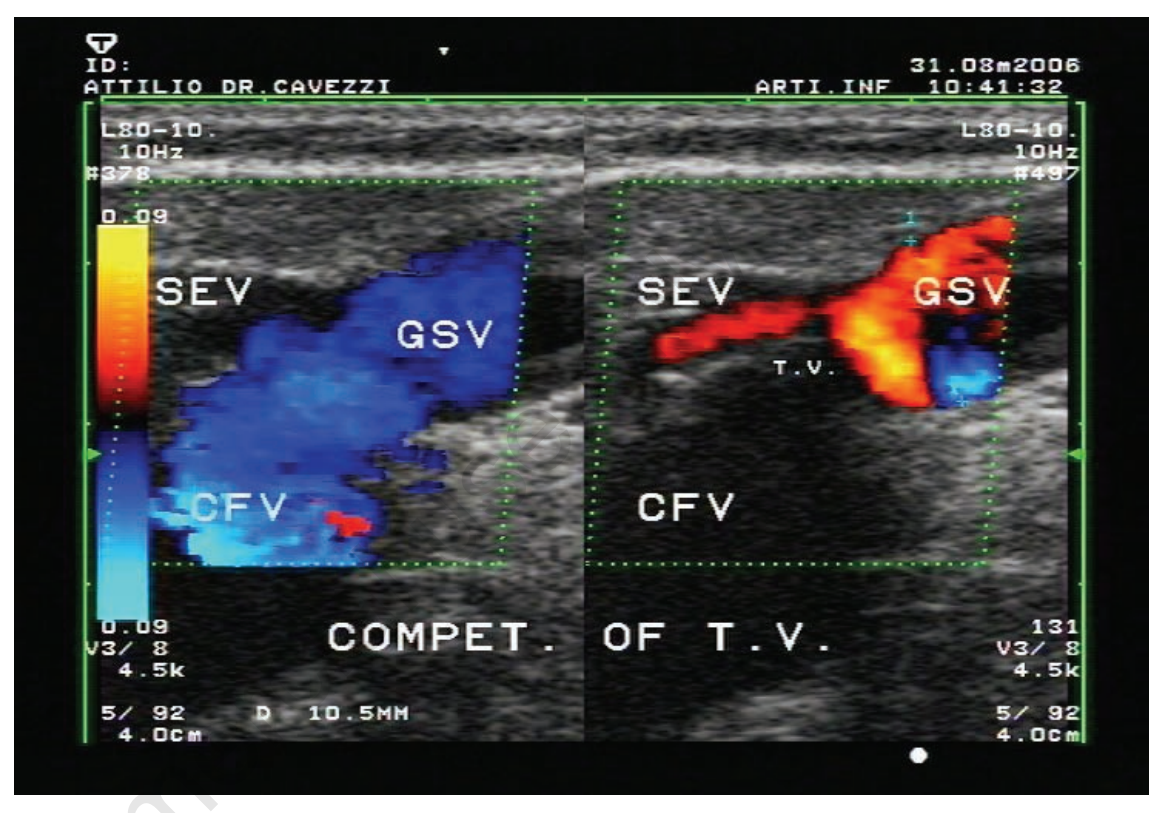

Figure 3. Color-duplex ultrasound of terminal valve competence at sapheno-femoral junction (and pelvic tributary retrograde flow during calf-release).

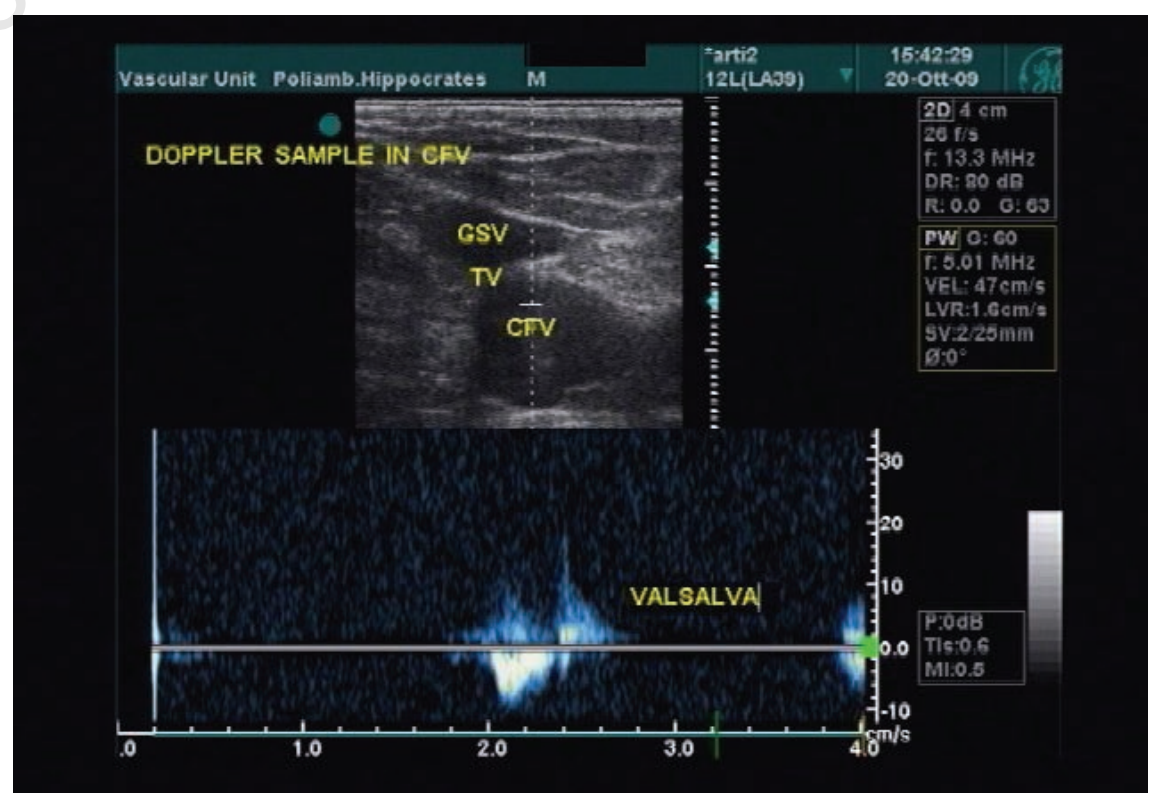

Figure 4. Duplex ultrasound (transverse scanning) of terminal valve competence: no reflux at Valsalva maneuver within common femoral vein. 
In our CDU explorations reflux was elicited both with manual calf muscle compression and Valsalva maneuver. The first gravitational gradient (squeezing) maneuver permits to highlight any retrograde flow with or without an escape point, whereas Valsalva maneuver (which is based on hyperpressure gradient) shows reflux only in presence of escape points. ${ }^{10,12}$

With reference to the intra-operative findings, in group A (TV competence at pre-operative CDU) limited blood leak occurred in a few patients after stage I and II during respiration, and not during Valsalva; this leak is probably the expression of the normal/physiologic drainage of the abdominal wall/pelvic tributaries within SFJ. Conversely two of the three patients who exhibited reflux from the open SFJ stump during hyperpressure maneuvers (Valsalva and iliaca fossa compression) after stage I and after stage II, were likely affected by pelvic vein insufficiency (Figures 4-6). After stage III only one patient of group A clearly showed reflux at hyperpressure maneuvers, which obviously relates to persistent TV incompetence (the false negative patient at pre-operative CDU exploration).

In group B (TV incompetence at pre-operative CDU) all patients exhibited reflux during respiration and during Valsalva and iliac fossa compression, and refluxes resulted qualitatively much more evident (in comparison to group A) at the visual control during the operations.

During the in vivo intra-operative assessment possible external interferences may have occurred, such as: patient position, variable geometry of the open SFJ stump, non-physiologic venous wall tension and cusp movements. Similarly the open SFJ stump compliance was obviously much higher than the physiologic one, which may have represented another difference with normal vein pathophysiology.

Anyway a great attention was given to maintain the normal SFJ anatomy and physiology during the intra-operative assessment, in order to minimize all those factors, which could potentially bias the final outcomes. The good correspondence between CDU and intraoperative findings (27 out of 28 cases, which corresponds to $94 \%$ accuracy, with $6 \%$ false negative rate), somehow show that the in vivo demonstration of TV competence/incompetence (Figure 7 and Video 1) has represented a reliable method to confirm adequacy of CDU investigation to diagnose this specific morphohemodynamic condition.

One single patient in group A showed intraoperative TV incompetence, after being diagnosed pre-operatively with TV competence with CDU. The objective over-complexity of investigating severely obese patients with CDU may be responsible for false/positives/negative findings at SFJ, as well as in other vein districts.

The limited sample size has not permitted any statistical analysis on our data; notwithstanding the intra-operative results match the CDU ones as overall. This prospective study was performed in 2003 and it included a limited number of patients; in fact the patients' recruitment was interrupted after few weeks, due to the complexity of the protocol and due to fact that the authors changed their strategy in patients with terminal valve competence, where crossectomy has been considered unnecessary. Having achieved adequate outcomes after the first 28 patients, as to the aim of the study, it was decided to limit the comparative study to the data, which were obtained until that time.

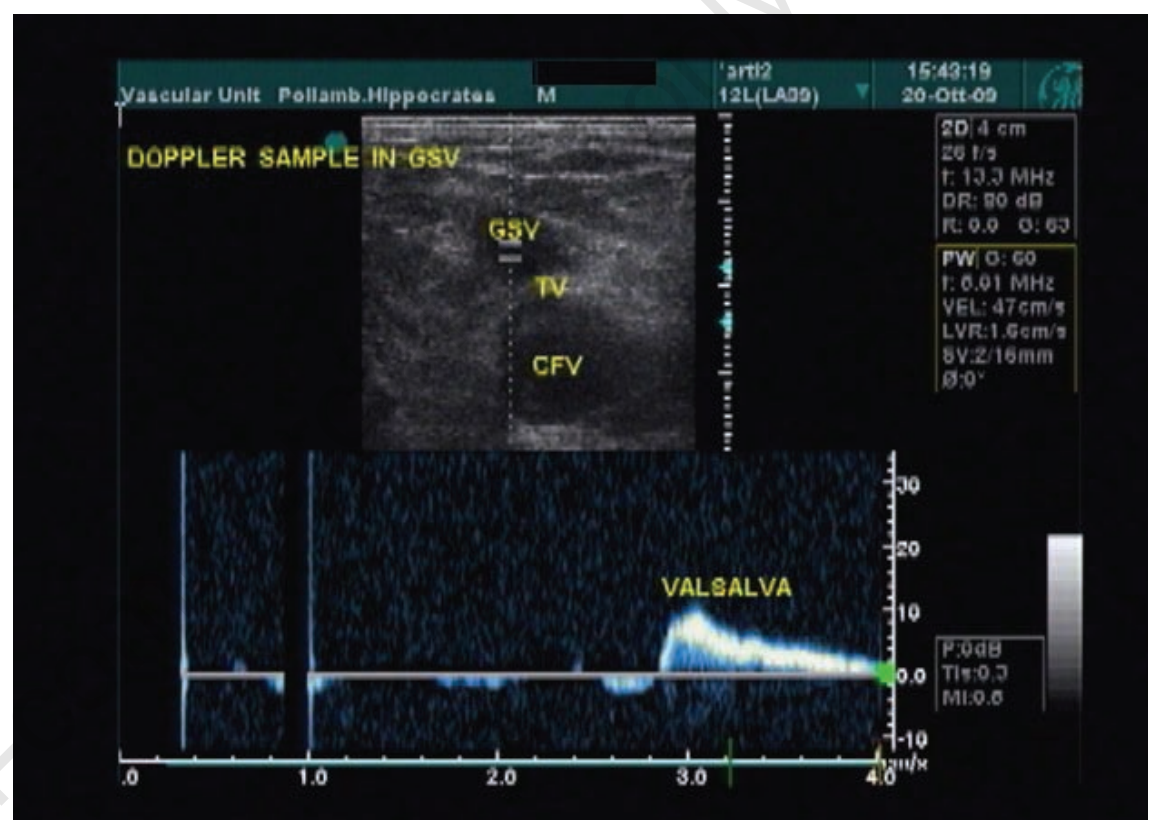

Figure 5. Same case of Figure 4: reflux during Valsalva maneuver within great saphenous vein just below terminal valve (pelvic vein insufficiency).

Table 1. Intra-operative assessment of the terminal valve of great saphenous vein (stage I-IV).

\begin{tabular}{|c|c|c|c|c|c|c|}
\hline & \multicolumn{4}{|c|}{$\begin{array}{c}\text { Group A } \\
\text { (18 patients with TV competence at CDU) }\end{array}$} & \multicolumn{2}{|c|}{$\begin{array}{c}\text { Group B } \\
\text { (10 patients with TV incompetence at CDU) }\end{array}$} \\
\hline & \multicolumn{2}{|c|}{ Respiration } & \multicolumn{2}{|c|}{$\begin{array}{l}\text { Valsalva man } \\
\text { and Iliac fossa compression }\end{array}$} & \multirow{2}{*}{$\begin{array}{l}\text { Respiration } \\
\text { Blood } \\
\text { leak }\end{array}$} & \multirow{2}{*}{$\begin{array}{l}\text { Valsalva man and lliac fossa } \\
\text { compression } \\
\text { Reflux }\end{array}$} \\
\hline & $\begin{array}{l}\text { Blood } \\
\text { leak }\end{array}$ & $\begin{array}{l}\text { No blood } \\
\text { Leak }\end{array}$ & Reflux & No reflux & & \\
\hline After stage I & 5 & 13 & 3 & 15 & 10 & 10 \\
\hline After stage II & 4 & 14 & 3 & 15 & 10 & 10 \\
\hline After stage III & 1 & 17 & 1 & 17 & 10 & 10 \\
\hline After stage IV & 0 & 18 & 0 & 18 & 0 & 0 \\
\hline
\end{tabular}

TV, terminal valve; CDU, color duplex ultrasound. 
Pre-treatment CDU investigation of GSV TV in varicose vein disease may address towards different therapeutic options. In case of TV competence, simple treatment of the refluxing varicose tributaries (e.g. with selective surgery or foam sclerotherapy) without any ablation of GSV trunk, would provide good outcomes at mid-term ${ }^{8,13}$ and generally speaking no SFJ treatments should be advisable. In fact first step of CHIVA 2 (which consists of disconnection of the uppermost refluxing tributary from GSV trunk and hook phlebectomy of the proximal segment of the varicose tributaries), or single phlebectomy $h$, achieve in the vast majority of the cases, after one-to-six months, the abolition of GSV trunk reflux and the GSV calibre reduction. ${ }^{14}$ Similarly ASVAL approach resulted in good clinical and CDU results at 4 years follow-up. ${ }^{13}$ These transient morphologic and hemodynamic changes ${ }^{15,16}$ are due to the abolition of the re-entry veins and thus to the reduction of compliance and of the retrograde volume In presence of TV competence a more favorable follow-up could be expected ${ }^{8}$ in these patients.

Of importance, any endovenous chemical or thermail ablation leaves the SFJ open, which may implicate that in cases of pre-treatment TV competence, mid-long term follow-up may be positively influenced, as the residual SFJ stump may have no reflux thanks to TV normal function. ${ }^{17}$ Sound data on this issue are still lacking, but ethiopathogenesis of recurrent varicose veins may somehow relate to the pre/post-treatment morpho-hemodynamic status of TV. ${ }^{17}$

In 2006 Cappelli $^{18}$ also demonstrated the fundamental role of the iliac-femoral valve, which is located in the deep veins above SFJ, as to GSV diameter and with reference to SFJ hemodynamics. In fact an absent or incompetent iliacfemoral valve (in combination with TV incompetence) is associated with mid-thigh GSV diameter over $7 \mathrm{~mm}$ in more than $50 \%$ of the cases. At the time of our study, in fact we did not included iliac-femoral valve assessment in our pre-operative CDU investigation.

In this observational comparative study, preoperative CDU investigation of TV at SFJ has resulted in coherent results, when compared to in vivo intraoperative TV assessment (Figure 7). As TV role in GSV disease has been proved to be of importance, scrupulous pre-treatment CDU investigation of TV could lead to more tailored therapies. A more conservative (less expensive), or, conversely, a more radical treatment could be planned according to the resulting CDU findings. Anyway it is auspicable that pre-therapy TV assessment should be an integral part of any scientific study aimed at producing proper evidence on GSV treatments, especially when midlong term data are provided.

A few final considerations could be drawn from this study: i) CDU investigation of SFJ

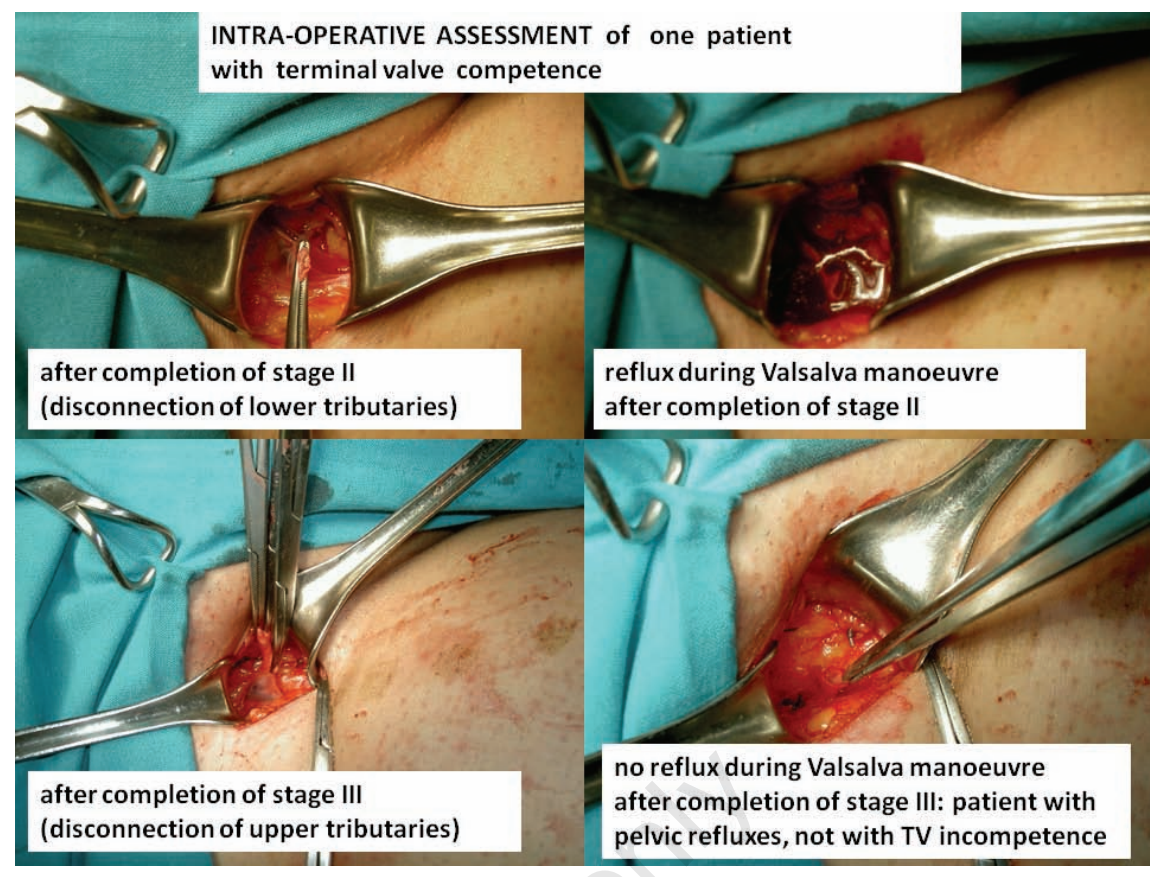

Figure 6. Intra-operative assessment of one patient with terminal valve competence: reflux till stage II completion and abolition of reflux after stage III.

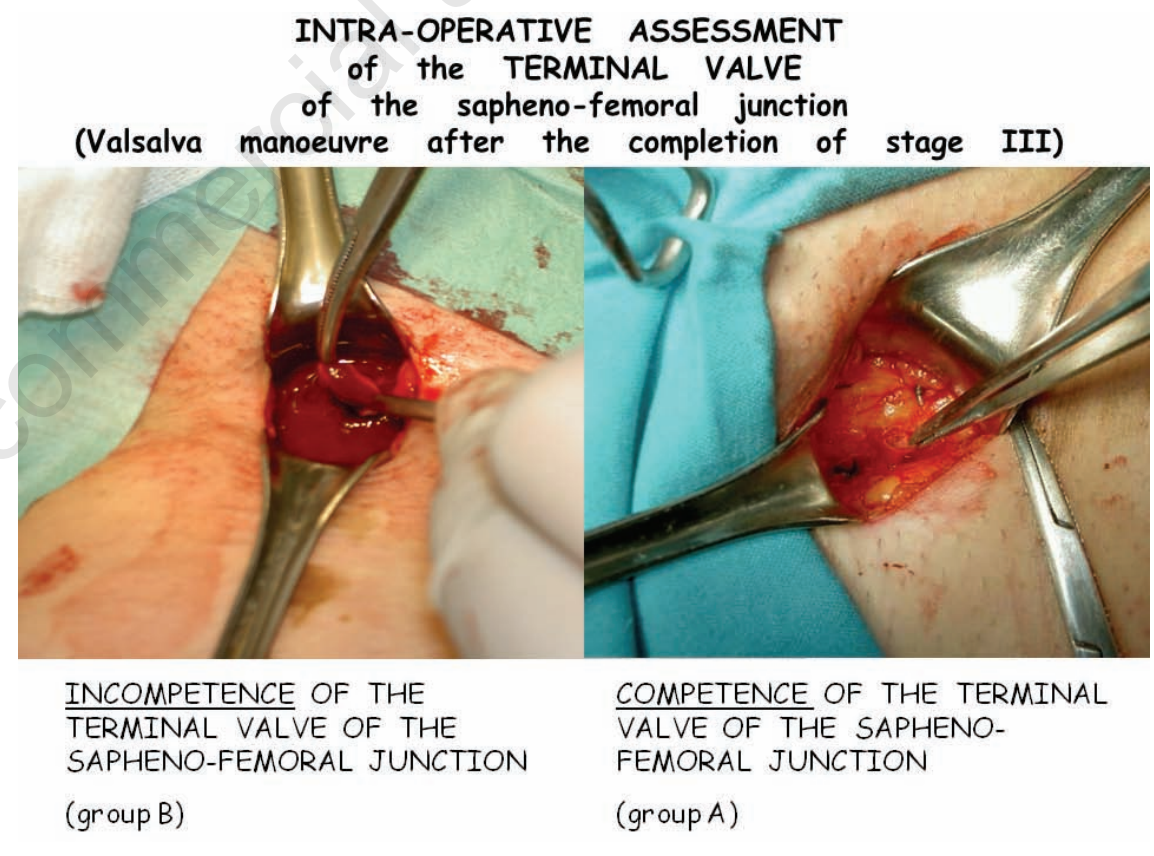

Figure 7. Comparative pictures of two different patients during intra-operative assessment.

and TV has proved to be accurate in the vast majority of the cases; ii) TV CDU assessment may lead to a saphenous junction (/trunk?) sparing therapy, as $40-50 \%$ of the varicose limbs with GSV reflux have a competent TV; iii) TV competence (hence GSV calibre below 6-7 $\mathrm{mm}$ in the vast majority of the cases) may explain the quite good short/mid term outcomes of the published literature on endovenous treatments, ${ }^{19-21}$ where the treated GSVs have $\mathrm{a} \leq 6 \mathrm{~mm}$ diameter in the vast majority of the treated patients.

Unfortunately no or little data are published on TV competence/incompetence in GSV treat- 
ment clinical trials, hence future prospective studies should systematically include more comprehensive morphology and hemodynamics information, if a more advanced diagnosis/therapy of primary and recurrent varicose veins has to be finalized. ${ }^{22}$

\section{References}

1. Somjen GM, Donlan J, Hurse J, et al. Venous reflux at the sapheno-femoral junction. Phlebology 1995;10:132-5.

2. Pieri A, Vannuzzi A, Duranti A, et al. Role central de la valvule pre-ostiale de la veine sapheene interne dans la genese des varices tronculaires des membres inferieurs. Phlebologie 1995;48:227-9.

3. Abu-Own A, Scurr JH, Coleridge Smith PD. Saphenous vein reflux without incompetence at the saphenofemoral junction. Br J Surg 1994;81:1452-4.

4. Cavezzi A, Labropoulos N, Partsch H, et al. A. Duplex ultrasound investigation of the veins in chronic venous disease of the lower limbs - UIP consensus document. Part II. Anatomy. Eur J Vasc Endovasc Surg 2006;31:288-99.

5. Coleridge-Smith P, Labropoulos N, Partsch $\mathrm{H}$, et al. Duplex ultrasound investigation of the veins in chronic venous disease of the lower limbs - UIP consensus document. Part I. Basic principles. Eur J Vasc Endovasc Surg 2006;31:83-92.

6. Caggiati A, Rippa Bonati M, Pieri A, Riva A. 1603-2003:four centuries of valves. Eur J Vasc Endovasc Surg 2004;28:439-41.

7. Mühlberger D, Morandini L, Brenner E. An anatomical studt of femoral vein valves near the saphenofemoral junction. J Vasc Surg 2008;48:994-9.

8. Zamboni P, Gianesini S, Menegatti E, et al. Great saphenous varicose vein surgery without saphenofemoral junction disconnection. Br J Surg 2010;97:820-5.

9. Cavezzi A, Carigi V, Collura M. Colour-flow duplex scanning as a pre-operative guide for mapping and for local anesthesia in varicose vein surgery. Phlebology 2000;15:24-9.

10. Cappelli M, Molino Lova R, Ermini S, Zamboni P. Hemodynamics of the sapheno-femoral junction. Patterns of reflux and their clinical implications. Int Angiol 2004;23:25-8.

11. Bernardini E, De Rango P, Piccioli R, et al. Development of primary superficial venous insufficiency: the ascending theory. observational and hemodynamic data from a 9-year experience. Ann Vasc Surg 2010;24:709-20.

12. Franceschi C, Zamboni P. Principles of venous haemodynamics. New York: Nova Science Publisher; 2009.

13. Pittaluga P, Chastanet S, Rea B, Barbe R. Midterm results of the surgical treatment of varices by phlebectomy with conservation of a refluxing saphenous vein. J Vasc Surg 2009;50:107-18.

14. Zamboni P, Cisno C, Marchetti F, et al. Reflux elimination without any ablation or disconnection of the saphenous vein. A haemodynamic model for venous surgery. Eur J Vasc Endovasc Surg 2001;21:361-9.

15. Escribano JM, Juan J, Bofill R, et al. Durability of reflux-elimination by a minimally invasive CHIVA procedure on patients with varicose veins. A 3-year prospective case study. Eur J Vasc Endovasc Surg 2003;25:159-63

16. Pichot 0, Sessa C, Bosson JL. Duplex imaging analysis of the long saphenous vein reflux: basis for strategy of endovenous obliteration treatment. Int Angiol 2002;21:333-6.

17. De Maeseneer M, Cavezzi A. Etiology and pathophysiology of varicose vein recurrence at the saphenofemoral or saphenopopliteal junction: an update. Veins and Lymphatics 2012;1:e4.

18. Cappelli M, Molino Lova R, Ermini S, et al. Hemodynamics of the sapheno-femoral complex: an operational diagnosis of proximal femoral valve function. Int Angiol 2006;25:356-60.

19. Lurie F, Creton D, Eklof B, et al. Prospective randomized study of endovenous radiofrequency obliteration (Closure procedure) versus ligation and stripping in a selected patient population (EVOLVeS Study). J Vasc Surg 2003;38:207-14.

20. Proebstle TM, Alm J, Göckeritz 0, et al. Three-year European follow-up of endovenous radiofrequency-powered segmental thermal ablation of the great saphenous vein with or without treatment of calf varicosities. J Vasc Surg. 2011;54:146-52.

21. Darke SG, Baker SJA. Ultrasound-guided foam sclerotherapy for the treatment of varicose veins. Br J Surg 2006;93:969-74.

22. De Maeseneer M, Pichot 0, Cavezzi A, et al. Duplex ultrasound investigation of the veins of the lower limbs after treatment for varicose veins - UIP consensus document. Eur J Vasc Endovasc Surg. 2011;42:89-102. 